\title{
RELATIVISMO DOS DIREITOS HUMANOS NO CENÁRIO GLOBAL E A PROPOSTA DO TRANSCONSTITUCIONALISMO
}

\author{
Ingrid Nayara Nogueira Bastos dos Santos \\ Aluna do Curso de Direito da FA7. Relato sob a orientação \\ do prof. Me. Ramon Negócio (FA7) \\ ingridnnbs@gmail.com
}

\section{INTRODUÇÃo}

O presente trabalho busca, a partir da metodologia da pesquisa teórica, apreciar uma discussão acerca dos Direitos Humanos, inicialmente tratando da questão de sua pretensão de universalismo, que coexiste com a realidade inegável de sua relativização. A partir de então, tal temática passa a ser analisada sob o prisma da semiótica, no que se refere às diversas atribuições de sentidos aos signos "direitos humanos", porquanto sua aplicação dependerá da interpretação a eles oferecida. Em seguida, será abordada a utilização simbólica de tais direitos, e como esta contribui para a ineficácia daqueles, embargando sua concretização. Outrossim, será discutido acerca do dissenso estrutural aliado com a necessidade de consenso procedimental dos direitos humanos, mas que diante da falta de tal consonância, o transconstitucionalismo parece se apresentar como a solução mais adequada para realizar a comunicação entre as interpretações dos direitos humanos.

\section{Universalismo e Relativismo Cultural dos Direitos Humanos e Seus Limites}

Uma impressão de universalidade dos direitos humanos parece advir de vários fatores, como por exemplo a noção de que são direitos devidos a um indivíduo simplesmente pelo fato de ele ser humano; no sentido de que é universal porque diz respeito a todos os seres humanos, de maneira igual e inalienável. No entanto, tal universalidade não esclarece se os direitos reconhecidos pela Declaração Universal de Direitos Humanos e pelos Pactos Internacionais de Direitos Humanos possuem no plano fático uma aplicabilidade universal. Para preservar a completa universalidade para os direitos básicos, o universalismo radical deveria dar preferência para as demandas das comunidades cosmopolitas, em detrimento das menos eminentes (DONNELLY, 2007). Por outro lado, um relativismo cultural sobre os direitos humanos se depararia com uma contradição lógica (p. 403), por causa da possibilidade da relativização dos direitos humanos quando estes na verdade ocorrem em razão da natureza humana, que é universal (AFONSO, 2009). Então, como relativizar algo que tem como principal fundamento algo universal? 
As diferentes sociedades podem ter atitudes semelhantes ou diferentes quanto às questões relativas aos direitos humanos, no entanto, sem um entendimento mais amplo sobre o assunto. A difusão dos mercados modernos e dos Estados burocráticos, com seus processos mais dificultosos que limitam as possibilidades de insucessos, mas que por isso tornam tudo mais lento, globalizou as mesmas ameaças à dignidade humana que eram experimentadas principalmente no contexto europeu. Os direitos humanos representam a reação mais eficiente já concebida, para atender a um amplo alcance, às ameaças à dignidade humana que os mercados econômicos e os Estados burocráticos tornaram praticamente universais, o que consistiria na universalidade funcional de tais direitos, que guarda sua relatividade.

Sua universalidade como direito internacional seria devido ao assentimento virtual dos Estados para sua incidência. Os Estados que sistematicamente violam os direitos humanos reconhecidos não perdem sua legitimidade no direito internacional, de modo que, exceto nos casos de genocídio, a soberania estatal ainda triunfa sobre esses direitos, o que impede a aplicação mais eficiente e compulsória de sanções em caso de desrespeito (DONNELLY, 2007).

No entanto, esse aspecto de universalidade é reproduzido mais a nível de teoria moral ou, no máximo, política. Mas, assim como explica John Rawls (apud DONNELLY, 2007), a partir de doutrinas variadas, pode-se chegar a um consenso. Este seria sobreposto; mais parcial do que completo. Assim sendo, os direitos humanos podem surgir a partir de um consenso justaposto de várias noções mais diversas, como política e justiça. Dessa forma, a universalidade de consensos sobrepostos seria um resultado da convergência tanto dentro como entre civilizações, proporcionando assim uma base para a consonância nos direitos da Declaração Universal.

O relativismo cultural, na discussão sobre direitos humanos, traz a relevância do respeito pelas diferenças culturais. No entanto, geralmente as culturas oferecem padrões absolutos de avaliação, sobre o que seja correto ou não para seus aderentes, o que é denominado de absolutismo cultural por Rhoda Howard-Hassmann. Tal relativismo cultural pode ser um antídoto para o universalismo deslocado, no entanto, há aspectos a serem analisados, tais como a questão da adaptação da moral e da aplicabilidade, em territórios diversos, das normas de direitos humanos; a consideração por parte de determinado grupo social de que sua moral não é infalível, para que possam, assim, aceitar posicionamentos diferentes dos seus próprios; relativismo intolerante e até mesmo genocida ser tão aceitável quanto um relativismo tolerante; a indiferença a argumentos políticos ou confusão destes com a moral.

Os direitos humanos teriam surgido a partir de um dissenso estrutural, advindo da sociedade moderna funcionalmente diferenciada, sendo tal desacordo em razão tanto da tentativa de integração sistêmica entre esferas de comunicação autônoma quanto por conta das diferenças de valores, de expectativas normativas, e de interesses de cada sistema. No entanto, não há um relativismo absoluto dos direitos humanos, porque, apesar do dissenso estrutural, existe um consenso procedimental em relação a eles (NEVES, 2005). O problema quanto a isso estaria justamente na falta de uma institucionalização adequada em três níveis de validade: pessoal, no que se refere ao consenso de procedimentos, material, sobre a identificação de sentido, e temporal, no que diz respeito à própria falta de normatização (p.10). E, mediante a falta ou fragilidade de procedimentos democráticos que assegurem o dissenso conteudísticos dos direitos humanos, há uma inclinação à negação ou repressão de tal dissenso e à exclusão de certos grupos do cenário político-jurídico, prejudicando a institucionalização dos direitos humanos quanto à inclusão e ao dissenso (p. 27). 


\section{Insuficiência da Semântica Universal dos Direitos Humanos Frente à Pragmática das Decisóes}

As sociedades, em geral, consideram a importância dos direitos humanos de acordo com suas variadas concepções de indivíduo e proteção devida a este. No entanto, sem uma compreensão mais abrangente acerca dos direitos humanos, reforçada e apoiada por um segmento de destaque de tais sociedades, como certas pessoas e instituições, a aplicação de tais direitos acaba sendo mais difícil (BAGU, 2011). Andrew Nathan menciona um "universalismo temperado", de caráter mais flexível, que leva em consideração que conceitos de direitos guardam diversas concepções passíveis de serem defendidas, e qualquer dessas percepções terá, por sua vez, várias implementações possíveis (DONNELLY, 2007). Os conceitos estabelecem múltiplas variações possíveis entre as compreensões ou concepções, as quais, por sua vez, restringem a diversidade de práticas que podem razoavelmente ser consideradas como implementações de determinados conceitos e concepções; no entanto, até mesmo alguns desvios das normas dos direitos humanos universais podem ser considerados legitimados. As diferentes ameaças refletem justamente as diferenças culturais até mesmo a nível de conceitos; os participantes do consenso sobreposto devem ter seus argumentos respeitados quando apresentarem limites e desvios em relação às normas internacionais se sua essência for condizente com os valores defendidos pelos direitos humanos.

É importante ressaltar que é necessário se ter uma noção mais clara acerca da semântica de direitos humanos e como esta é utilizada hodiernamente, e, para tanto, é preciso um pouco mais de esclarecimento sobre as partes da semiótica (sintaxe, semântica e pragmática). A sintaxe estuda a relação dos signos entre si, de modo que é a teoria da construção da própria linguagem. A semântica seria o estudo dos signos e sua relação com os objetos que designam, de modo que, para os enunciados terem sentido, devem efetivamente poder ocorrer, sendo empiricamente verificáveis. A partir da análise semântica do que seja verdade, torna-se possível selecionar uma verdade objetiva, afastando as significações ideológicas à medida que consideram sem sentido aqueles enunciados que não possuem referenciais empíricos. Já a pragmática consistiria no estudo dos signos com os indivíduos que os utilizam, no que diz respeito ao modo de significar, a como a linguagem pode ser utilizada, ou a quais as funções desta (WARAT, 1995).

Trazendo tal discussão para os direitos humanos, é necessário realizar um estudo sobre sua sintaxe, semântica e pragmática, porquanto tal designação é utilizada muitas vezes de forma equivocada ou para legitimar discursos de poder, sendo ainda atribuída aos direitos humanos uma carga axiológica que não condiz com sua pragmática. Os atores internacionais podem repensar as questões de direitos humanos, e, a partir disso, criar novos significados para tais direitos, ou mesmo ignorando a semântica a eles atribuída de forma predominante no cenário internacional. A semântica dos direitos humanos pode até ter pretensões universais, mas sua aplicabilidade, sua própria pragmática, não demonstra tal universalidade; isso pode se dar em razão de concepções diversas sobre o sentido do que seja de fato direitos humanos, e, assim, uma relação de diálogo entre as decisões dos tribunais. Por isso que o diálogo entre decisões (também é pragmática) integra mais que tratados internacionais.

\section{Globalização, Conexão de Ordens Jurídicas, Transconsti- tucionalismo e Utilização Simbólica dos Direitos Humanos}

Há um sistema jurídico de níveis múltiplos, no qual ocorre um transconstitucionalismo pluridimensional, resultado da observação de uma mesma questão jurídica por diversas ordens, de 
modo que são oferecidas diversas soluções para um mesmo problema, enriquecendo a discussão. Assim sendo, seria prejudicial um fechamento cognitivo de uma ordem para com as demais, o que pode impedir que seja encontrada uma solução mais adequada. O transconstitucionalismo seria, portanto, um modelo que permitiria uma análise mais eficiente dessas questões (NEVES, 2009).

Deve ser devidamente abordada a questão da fragmentação dos setores sociais globais (TEUBNER e FISCHER-LESCANO, 2004), os regimes próprios (que tratam de temas específicos), cada vez mais independentes das normas gerais de direito internacional, e as repercussões disso nos direitos humanos, que podem funcionar inclusive como elemento unificador entre essas ordens.

Uma visão mais ampla de direitos humanos pode passar uma vagueza desse conceito, podendo impedir uma aplicação ou mesmo um entendimento mais efetivo sobre o que seja isso; não sendo adequada também uma concepção muito estrita, pautada no liberalismo. Há uma expectativa normativa (que não se modifica frente às frustrações) em relação aos direitos humanos, com sua aplicação destoante da prática, com uma realidade na qual há uma violação absurda à dignidade da pessoa humana com a exclusão de significativas parcelas da sociedade, que subsiste em condições degradantes. Haveria ainda a diferenciação entre os direitos humanos frágeis e os fortes (que já estão positivados e implementados processualmente no contexto do sistema jurídico mundial de níveis múltiplos, como no jus cogens) (NEVES, 2009).

Além disso, deve ser apreciada também a questão de, com o uso simbólico dos direitos humanos (NEVES, 2005), poder haver um deslocamento de sentido para uma outra esfera de significações, de modo que, por exemplo, mesmo os direitos humanos pertencendo à esfera jurídica, seu sentido político ser tão forte ao ponto de ofuscar o aspecto jurídico de fato. A significativa falta de eficácia normativo-jurídica proporcionada pela utilização simbólica dos direitos humanos gera efeitos que, a partir de uma manipulação política, mantêm essa situação de ineficácia, ao mesmo tempo em que incentiva movimentos para a criação e proteção de tais direitos. Isso caracterizaria a força ambivalente do uso simbólico dos direitos humanos (p. 27).

Há ainda os perigos da desdiferenciação (NEVES, 2009), que acontece quando um sistema fica subordinado a outro, sendo afetada assim sua autopoiese, seu enclausuramento e sua autonomia e independência, uma vez que agora se encontra a depender de outro, e, no caso dos direitos humanos, apesar de terem que atender às demandas relacionadas a outros sistemas, a subordinação deste sistema ao da política ou economia seria totalmente discordante com o que é proposto por tais direitos, até porque deve haver uma comunicação intersistêmica, e não dependência e submissão de um sistema para com outro; os direitos humanos podem ser fator de ligação entre o sistema do direito e os demais, mas não devem ser utilizados como uma lacuna que dê oportunidade de corrupção sistêmica.

\section{Considerações Finais}

Diante da problemática apresentada, pretende-se desenvolver hipóteses de como lidar com a atual conjuntura dos direitos humanos. São levantados questionamentos tais como: até que ponto pode-se alegar aspectos particulares e internos para justificar uma aplicação diferenciada dos direitos humanos? Como pode ser desenvolvido um consenso procedimental para a concretização de tais direitos? De que maneira o transconstitucionalismo pode estabelecer um diálogo entre os diversos atores e ordens internacionais? Além disso, como a observação semântica e pragmática poderia desmascarar discursos meramente políticos acerca dos direitos humanos, que visam apenas legitimar certas práticas de poder? De que maneira pode ocorrer um diálogo entre as decisões 
dos diversos tribunais relativas aos problemas de direitos humanos? E, ainda, como os direitos humanos podem funcionar como fator de unificação entre o cenário internacional fragmentado, e como fator de inclusão para os indivíduos e atores subincluídos no contexto internacional?

\section{REFERÊNCIAS}

AFONSO, Henrique Weil. Unidade e Fragmentação do Direito Internacional: o papel dos Direitos Humanos como elemento unificador. Revista Eletrônica de Direito Internacional, v. 4, p. 53-90, 2009.

AFONSO, Henrique Weil. MAGALHÃES, José Luis Quadros de. Direito Internacional Fragmentado e Proteção aos Direitos Humanos: As repercussões para o desenvolvimento dos Estados. Revista das Faculdades Integradas Vianna Júnior. Vianna Sappiens. Volume 2, número 2.

BAGU, Kajit John. Ideological Refuge V Jurisprudence of Insurgency: Cultural Relativism and Universalism in the Human Rights Discourse. Warwick Student Law Review. 2011.

DONNELLY, Jack. The Relative Universality of Human Rights. Human Rights Quarterly, Volume 29, Number 2, May 2007, pp. 281-306 (Article).

NEVES, Marcelo. Transconstitucionalismo. São Paulo: Editora WMF Martins Fontes, 2009.

. A Força Simbólica dos Direitos Humanos. Revista Eletrônica de Direito do Estado,

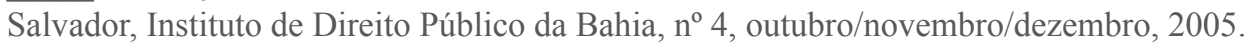
Disponível em: < http://www.direitodoestado.com/revista/REDE-4-OUTUBRO-2005-MARCELO\%20NEVES.pdf>. Acesso em: 14 maio 2013.

TEUBNER, Gunther; FISCHER-LESCANO, Andreas. Regime-collisions: the vain search for legal unity in the fragmentation of global law. Michigan Journal of International Law, Vol. 25, pp. 999-1045, summer 2004.

WARAT, Luis Alberto. O Direito e sua Linguagem. 2. versão; edição aumentada. Porto Alegre: Sergio Antonio Fabris Editor, 1995. 
